\title{
Functional analysis of mRNA scavenger decapping enzymes
}

\author{
SHIN-WU LIU, ${ }^{1}$ XINFU JIAO, ${ }^{1}$ HUDAN LIU, ${ }^{1}$ MEIGANG GU, ${ }^{2}$ CHRISTOPHER D. LIMA, ${ }^{2}$ and \\ MEGERDITCH KILEDJIAN ${ }^{1}$ \\ ${ }^{1}$ Department of Cell Biology and Neuroscience, Rutgers University, Piscataway, New Jersey 08854, USA \\ ${ }^{2}$ Structural Biology Program, Sloan-Kettering Institute, New York, New York 10021, USA
}

\begin{abstract}
Eukaryotic cells primarily utilize exoribonucleases and decapping enzymes to degrade their mRNA. Two major decapping enzymes have been identified. The hDcp2 protein catalyzes hydrolysis of the $5^{\prime}$ cap linked to an RNA moiety, whereas the scavenger decapping enzyme, DcpS, functions on a cap structure lacking the RNA moiety. DcpS is a member of the histidine triad (HIT) family of hydrolases and catalyzes the cleavage of $\mathrm{m}^{7} \mathrm{GpppN}$. HIT proteins are homodimeric and contain two conserved 100-amino-acid HIT fold domains with independent active sites that are each sufficient to bind and hydrolyze cognate substrates. We carried out a functional characterization of the DcpS enzyme and demonstrate that unlike previously described HIT proteins, DcpS is a modular protein that requires both the core HIT fold at the carboxyl-terminus and sequences at the amino-terminus of the protein for cap binding and hydrolysis. Interestingly, DcpS can efficiently compete for and hydrolyze the cap structure even in the presence of excess eIF4E, implying that DcpS could function to alleviate the accumulation of complexes between elF4E and cap structure that would otherwise accumulate following mRNA decay. Using immunofluorescence microscopy, we demonstrate that DcpS is predominantly a nuclear protein, with low levels of detected protein in the cytoplasm. Furthermore, analysis of the endogenous hDcp2 protein reveals that in addition to the cytoplasmic foci, it is also present in the nucleus. These data reveal that both decapping enzymes are contained in the nuclear compartment, indicating that they may fulfill a greater function in the nucleus than previously appreciated.
\end{abstract}

Keywords: mRNA decay; mRNA decapping; HIT motif; cytoplasmic foci

\section{INTRODUCTION}

Turnover of mRNA is a regulated process that influences gene expression. The major mRNA degradation pathways in eukaryotes involve exonucleolytic decay initiated by deadenylation that is followed by either a continuation of $3^{\prime}$ to $5^{\prime}$ decay and decapping, or decapping and subsequent $5^{\prime}$ to 3' decay (Parker and Song 2004). The scavenger decapping enzyme, DcpS in human and Dcslp in Saccharomyces cerevisiae, hydrolyzes the resulting cap structure following decay by the $3^{\prime}$ to $5^{\prime}$ decay pathway (Liu et al. 2002). Hydrolysis of capped mRNA primarily involves the Dcp2 protein in mammalian cells (Lykke-Andersen 2002; van Dijk et al. 2002; Wang et al. 2002) and the Dcp1p/Dcp2p enzyme complex in yeast cells (Steiger et al. 2003).

Reprint requests to: Megerditch Kiledjian, Department of Cell Biology and Neuroscience, Rutgers University, Piscataway, NJ 08854, USA; e-mail: kiledjia@biology.rutgers.edu; fax: (732) 445-0104.

Article published online ahead of print. Article and publication date are at http://www.rnajournal.org/cgi/doi/10.1261/rna.7660804.
Each decapping enzyme possesses a distinct hydrolase motif that is essential for decapping. The Dcp2 protein contains a nucleotide diphosphate linked to an $\mathrm{X}$ moiety (Nudix) hydrolase motif (Dunckley and Parker 1999; van Dijk et al. 2002; Wang et al. 2002), whereas DcpS contains a histidine triad (HIT) hydrolase motif required for its decapping activity (Liu et al. 2002). The Nudix motif was originally identified in a class of hydrolase proteins and shown to be critical for pyrophosphatase activity (Koonin 1993; Mejean et al. 1994). A Nudix motif consisting of a 23-amino-acid consensus sequence within a larger Nudix fold (Bessman et al. 1996) was shown to be critical for Dcp2 decapping activity (Dunckley and Parker 1999; van Dijk et al. 2002; Wang et al. 2002). Interestingly, the human Dcp2 (hDcp2) protein is an RNA-binding protein that only hydrolyzes the cap structure within the context of a linked RNA moiety, requiring both an RNA-binding property and the Nudix motif to recognize and hydrolyze capped RNA (Piccirillo et al. 2003). The prerequisite for RNA binding precludes hDcp 2 from functioning on cap structure and restricts its activity to capped RNA. 
The HIT motif present in the DcpS decapping enzyme is characterized by three histidine residues separated by hydrophobic amino acids (Seraphin 1992). This motif is contained within a larger 100-amino-acid HIT fold (Brenner 2002). Structural analysis of several HIT proteins revealed that these proteins exist as homodimers through formation of a 10 -stranded antiparallel $\beta$-sheet. Each HIT protomer contains an active site and nucleotide binding pocket that coordinates the pyrophosphate bond with respect to the three histidines of the catalytic HIT motif (Brenner et al. 1997; Lima et al. 1997; Pace et al. 1998). In contrast to hDcp2, which functions on capped RNA, DcpS does not appear to function on capped RNA and functions on capped oligonucleotides shorter than 10 nucleotides (Liu et al. 2002). This property led to the initial hypothesis that DcpS is a scavenger decapping enzyme that hydrolyzes resulting cap dinucleotide following mRNA decay (Nuss et al. 1975; Nuss and Furuichi 1977; Wang and Kiledjian 2001). This hypothesis was subsequently confirmed with a mammalian in vitro RNA decay system where decapping products were detected following prior deadenylation and exosome-mediated decay of the RNA (Rodgers et al. 2002). Furthermore, cap structure was shown to accumulate in the $d c s 1 \Delta$ S. cerevisiae strain (Liu et al. 2002). DcpS activity can be copurified with the exosome $3^{\prime}$ to $5^{\prime}$ exoribonuclease complex, implying a coordinated link between decay of the mRNA body and the final decapping step (Wang and Kiledjian 2001). Interestingly, in S. cerevisiae there are two homologous proteins, Dcs1p and Dcs2p. Although both are highly related and share an equivalent level of identity with DcpS, only Dcs1p is capable of hydrolyzing the cap struc- ture, whereas Dcs2p does not have a detectable level of decapping activity.

In this report we demonstrate that DcpS decapping activity is dependent on two distinct and modular domains of the protein, one that contains a HIT fold and the second, an essential N-terminal domain. We also demonstrate that in addition to the previously reported presence of DcpS and hDcp 2 in the cytoplasm, both are predominantly nuclear proteins, indicating that the two main decapping enzymes could regulate cap hydrolysis in both cellular compartments.

\section{RESULTS}

\section{Regions outside the HIT hydrolase fold are critical for decapping}

The S. cerevisiae Dcs1p and Dcs2p proteins share 65\% identity and $90 \%$ similarity, with the highest degree of identity observed within the C-terminal HIT hydrolase domain of the two proteins. Despite this high degree of identity and the fact that the HIT fold was shown in previously characterized HIT proteins to contain both nucleotide-binding and hydrolase activities (Brenner et al. 1999; Brenner 2002), only Dcs1p has detectable cap hydrolysis activity (Liu et al. 2002). To determine whether the Dcs2p HIT motif is competent to hydrolyze a methylated cap structure and whether regions of the protein outside the HIT motif are required for cap hydrolysis, the N-terminal and C-terminal segments of the two proteins were swapped. A schematic of the two proteins is shown in Figure 1A, along with the domainswapped proteins. One fusion protein consisted of the $\mathrm{N}$ -
A

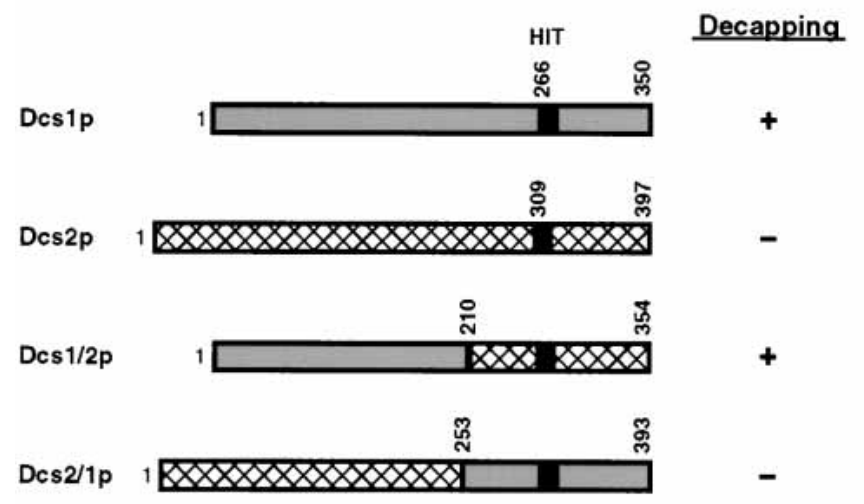

B

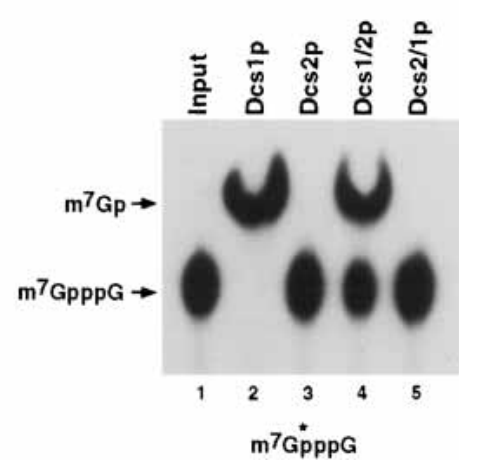

FIGURE 1. Regions outside the HIT hydrolase fold are critical for scavenger decapping activity. (A) Dcslp and Dcs $2 p$ are represented schematically in gray and hatch bars, respectively. The chimeric Dcs $1 / 2 \mathrm{p}$ and Dcs $2 / 1 \mathrm{p}$ proteins containing the swapping portions are indicated, with the number above the schematic representing the amino acid at the site of protein fusion. The black box denotes the 6-amino-acid HIT motif with the amino acid position indicated above. A summary of decapping activity for each protein is shown on the right, where "+" and "-" represent the ability or inability to catalyze cap structure hydrolysis, respectively. (B) The presence of Dcs $1 \mathrm{p}$ N-terminus corresponds to decapping. A decapping assay using 0.5 pmoles of each histidine-tagged recombinant protein was carried out at $37^{\circ} \mathrm{C}$ for 15 min using ${ }^{32} \mathrm{P}$-labeled cap analog where the first phosphate relative to the methylated guanosine is labeled $\left(\mathrm{m}^{7} \mathrm{G}^{*} \mathrm{pppG}\right)$ as substrate. Reaction products were resolved on PEI TLC plates. Migration of unlabeled cap analog substrate and $\mathrm{m}^{7} \mathrm{GMP}$ product was detected by UV shadowing and is shown at the left. A schematic of the ${ }^{32} \mathrm{P}$-labeled cap analog substrate is shown at the bottom, with the labeled phosphate denoted by * 
terminal half of Dcslp linked to the C-terminal half of $\operatorname{Dcs} 2 \mathrm{p}(\mathrm{Dcs} 1 / 2 \mathrm{p})$; the second consisted of the N-terminal half of Dcs2p fused to the C-terminal half of Dcs1p (Dcs2/ $1 \mathrm{p})$. The capacity of each recombinant histidine-tagged protein to hydrolyze cap structure labeled with ${ }^{32} \mathrm{P}$ at the first phosphate relative to the methylated guanosine ( $\mathrm{m} 7 \mathrm{G}^{*} \mathrm{pppG}$ ) was tested, and the products were resolved by polyethylenimine (PEI) cellulose thin-layer chromatography (TLC). Consistent with our previous findings (Liu et al. 2002), Dcs1p was capable of hydrolyzing the cap structure whereas Dcs2p was not (Fig. 1B, lanes 2,3). However, a chimeric protein containing the $\mathrm{N}$-terminus of Dcs1p and the HIT motif containing C-terminal segment of Dcs2p was capable of catalyzing cap hydrolysis, whereas the converse protein containing the $\mathrm{N}$-terminus of Dcs $2 \mathrm{p}$ linked to the C-terminus of Dcs1p was not functional (Fig. 1B, cf. lanes 4 and 5). These data demonstrate that N-terminal domains of Dcs proteins mediate their decapping potential.

\section{The amino terminus of Dcs1p and DcpS is critical for decapping}

To further refine the region within the N-terminus of Dcslp that was essential for decapping, a series of $\mathrm{N}$-terminal truncation proteins were generated (Fig. 2A). Removal of the N-terminal 40 amino acids of Dcs1p (Dcs1 $\left.\mathrm{p}^{\Delta \mathrm{N} 40}\right)$ had a deleterious consequence on decapping where no decapping was detected (Fig. 2B, lane 3). Conversely, removal of 65 residues at the $\mathrm{C}$-terminus of the protein that still retained the HIT hydrolase fold was still capable of decapping, albeit with lower efficiency (Fig. 2B, lane 5). These data further demonstrate a requirement for the $\mathrm{N}$-terminus of Dcslp in decapping and implicate the first 40 amino acids as an essential component of the Dcs1p decapping activity.

The requirement of the $\mathrm{N}$-terminus in decapping was also tested for the human DcpS protein. Amino acid sequence alignment of DcpS with Dcs1p indicates that DcpS contains a 33-amino-acid extension at the N-terminus (data not shown). We first determined whether this extended region is required for DcpS function. A schematic of the recombinant proteins used for this set of experiments is shown in Figure 2C. Removal of the N-terminal 33 amino acids of DcpS $\left(\mathrm{DcpS}^{\Delta \mathrm{N} 33}\right)$ did not have an adverse affect on decapping (Fig. 2D, lane 3). However removal of sequences up to amino acid $72\left(\mathrm{DcpS}^{\Delta \mathrm{N} 71}\right.$ which is analogous to the Dcs $1 \mathrm{p}^{\Delta \mathrm{N} 40}$ ) completely abrogated decapping activity of the truncated protein (Fig. 2D, lane 4), demonstrating the significance of the N-terminal domain for the human DcpS
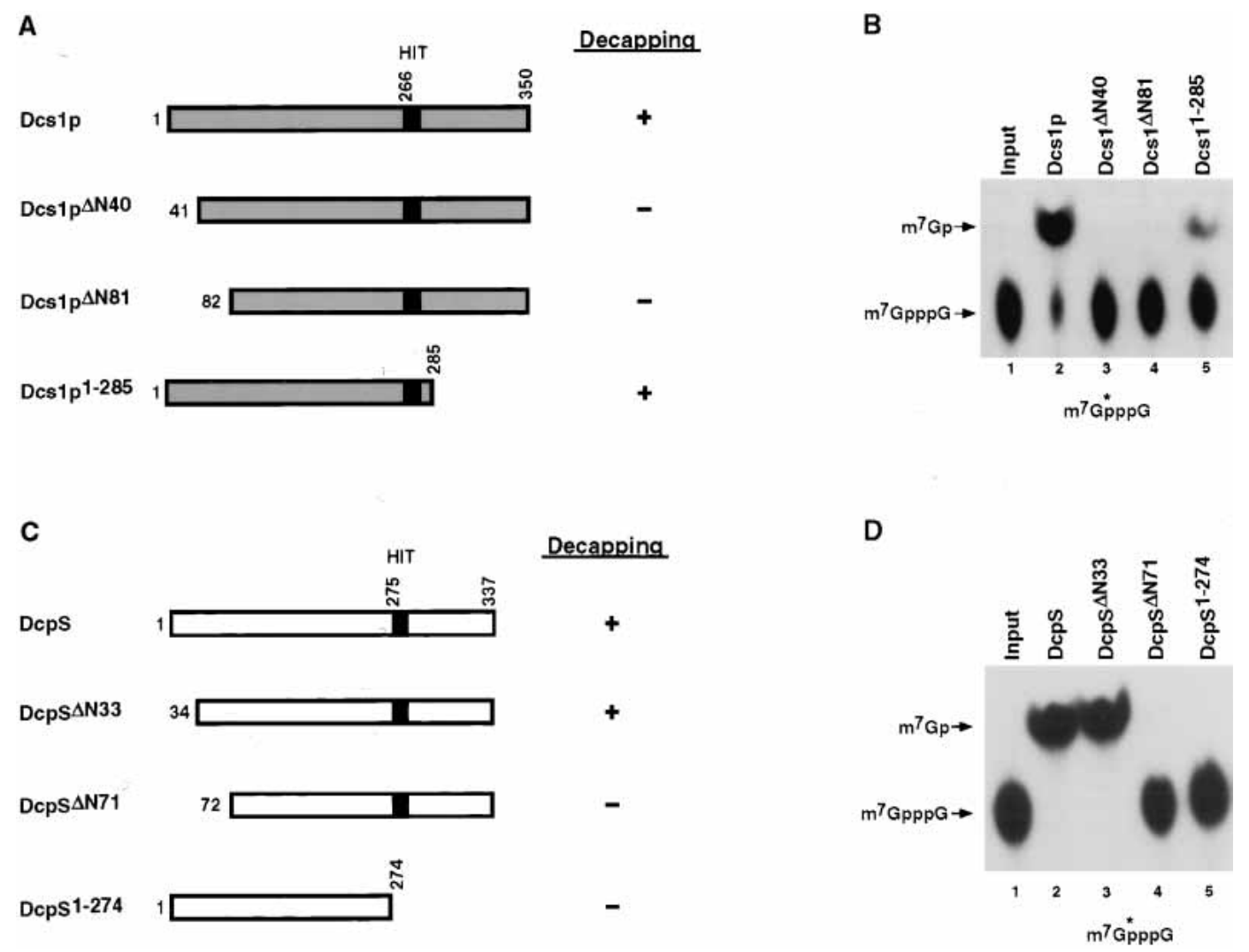

FIGURE 2. The N-termini of Dcslp and DcpS are critical for decapping. (A) A schematic of Dcslp and its truncated derivatives is shown. (B) Decapping activity obtained from each protein represented in panel $A$. (C) A schematic of the human DcpS protein and its truncated derivatives is shown; the corresponding decapping activity for each protein is shown in D. Labeling and assay conditions are as described in the Figure 1 legend. 
decapping protein as well. As expected, a C-terminal truncation removing the HIT motif also resulted in an enzymatically inactive protein (Fig. 2D, lane 5). Together, these data demonstrate that both the HIT motif and sequences at the N-terminus of DcpS and Dcs1p are required for the decapping activity of these proteins.

\section{DcpS is a modular protein whose activity can be reconstituted in trans}

The above data suggest that both the N-terminus and the C-terminus of DcpS are essential for decapping. In a related study, we obtained the crystal structure of DcpS, which revealed that the protein consisted of an N-terminal domain and a C-terminal domain separated by a hinge region (Gu et al. 2004; also see Discussion). To test whether DcpS can consist of two modular domains that can form a decapping enzyme, two halves of the human DcpS protein separated at the hinge region were generated and tested for decapping. Consistent with the above data, a protein containing the first 147 amino acids of DcpS, corresponding to the N-terminal domain lacking the HIT motif, was unable to hydrolyze the ${ }^{32} \mathrm{P}$-labeled cap structure substrate (Fig. 3, lane 3). Similarly, the C-terminal 189 amino acids of the protein containing the complete HIT hydrolase fold were also incompetent to hydrolyze the labeled cap structure (Fig. 3, lane 4). Interestingly, reconstitution of the two halves of the protein in trans generated a functional decapping activity (Fig. 3, lane 5). We conclude that DcpS contains at least two distinct modular domains that together generate a functional decapping enzyme.

\section{The DcpS N-terminal domain facilitates cap binding}

The inability of N-terminal truncated DcpS protein to hydrolyze the cap could be due to either the inability to bind

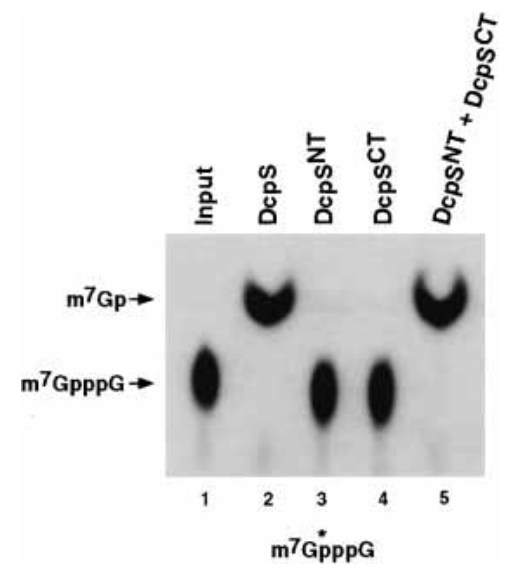

FIGURE 3. DcpS is a modular protein. A decapping assay using the $\mathrm{N}$-terminal 147 amino acids of $\mathrm{DcpS}\left(\mathrm{DcpS}^{\mathrm{NT}}\right)$ or the C-terminal 189 amino acids spanning residues $149-337\left(\right.$ DcpS $\left.^{\mathrm{CT}}\right)$ individually or both simultaneously in trans (lane 5) is shown. Five pmoles of DcpS was used in lane 2; $1 \mu \mathrm{g}$ of each truncated protein was used in lanes 3-5. Labeling and assay conditions are as described in the Figure 1 legend.

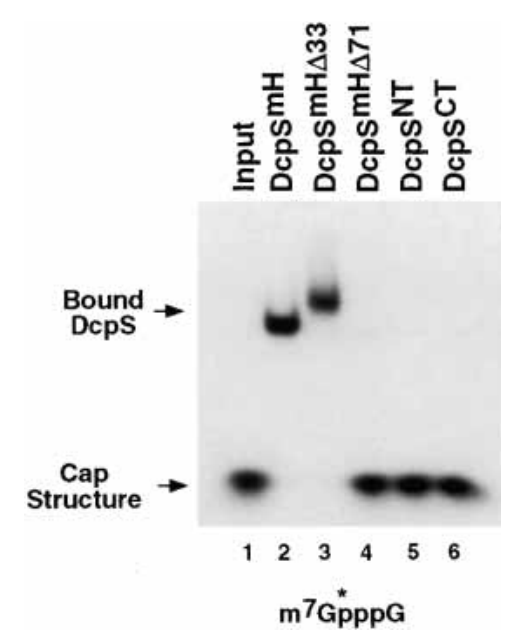

FIGURE 4. DcpS N-terminus facilitates cap binding. An EMSA was used to test the ability of DcpS and its truncated derivatives to bind ${ }^{32}$ P-labeled cap analog. Recombinant DcpS or the truncated derivatives removing N-terminal residues of 33 and 71 amino acids contain the HIT motif mutant substitution of an asparagine for the histidine at amino acids $277\left(\mathrm{DcpS}^{\mathrm{mH}}, \mathrm{DcpS}^{\mathrm{mH} \Delta 33}\right.$, and $\mathrm{DcpS}{ }^{\mathrm{mH} \Delta 71}$ respectively) were used. Proteins with a mutant HIT motif were used to uncouple cap binding and hydrolysis to enable detection of binding. $\mathrm{DcpS}^{\mathrm{NT}}$ represents the DcpS protein from amino acids $1-147$, and $\operatorname{DcpS}^{\mathrm{CT}}$ contains amino acids 149-337. The cap structure substrate and bound DcpS-cap structure complex are indicated by the arrows on the left, and a schematic of the substrate is shown at the bottom, where ${ }^{\star}$ denotes the ${ }^{32} \mathrm{P}$. The recombinant proteins used in lanes 3,4 contain a histidine tag at their amino terminus, whereas the histidine tag was removed from the recombinant proteins used in lanes 2,5,6 (see Materials and Methods).

the cap substrate, or the inability to hydrolyze the cap once it binds the substrate. To distinguish between these two possibilities, we used an electrophoretic mobility shift assay (EMSA) with DcpS and ${ }^{32} \mathrm{P}$-labeled cap structure. The DcpS $\mathrm{N}$-terminal truncation proteins, $\mathrm{DcpS}^{\Delta \mathrm{N} 33}$, which was competent to hydrolyze the cap structure, and $\mathrm{DcpS}^{\Delta \mathrm{N} 71}$, which was unable to hydrolyze the cap structure, were tested for their ability to bind the cap. A mutation substituting an asparagine for the active site histidine $\left(\mathrm{DcpS}^{\mathrm{mH}}\right)$ at amino acid 277 within the HIT motif was introduced into these constructs to render the resulting proteins inactive for hydrolysis activity (Liu et al. 2002) and enable detection of cap binding. Full-length $\mathrm{DcpS}^{\mathrm{mH}}$ and $\mathrm{DcpS}^{\mathrm{mH} \Delta \mathrm{N} 33}$, both of which would be expected to contain decapping activity in the absence of the histidine 277 substitution (Fig. 2), were capable of binding the cap structure as demonstrated by the slower migration on the ${ }^{32} \mathrm{P}$-labeled cap structure substrate (Fig. 4, lanes 2,3). Binding to cap structure was not detected with the DcpS ${ }^{\mathrm{mH} \Delta \mathrm{N71}}$ protein (Fig. 4, lane 4) nor with the individual N-terminal (Fig. 4, lane 5) and C-terminal (Fig. 4, lane 6) domains under these assay conditions. These results demonstrate that an intact N-terminal domain is necessary but not sufficient for binding of DcpS to the cap structure. 


\section{DcpS specifically hydrolyzes cap structure relative to capped RNA}

We previously reported that DcpS functioned on capped RNAs 10 nt or smaller (Liu et al. 2002). However, Nhm1p, the Schizosaccharomyces pombe homolog of DcpS, was recently reported as a decapping enzyme capable of catalyzing hydrolysis of capped RNA (Salehi et al. 2002). To more precisely address the specificity of DcpS for cap structure versus capped RNA, a titration of DcpS was carried out with the two different substrates. As shown in Figure 5A, DcpS efficiently hydrolyzed the ${ }^{32} \mathrm{P}$-labeled cap structure, where

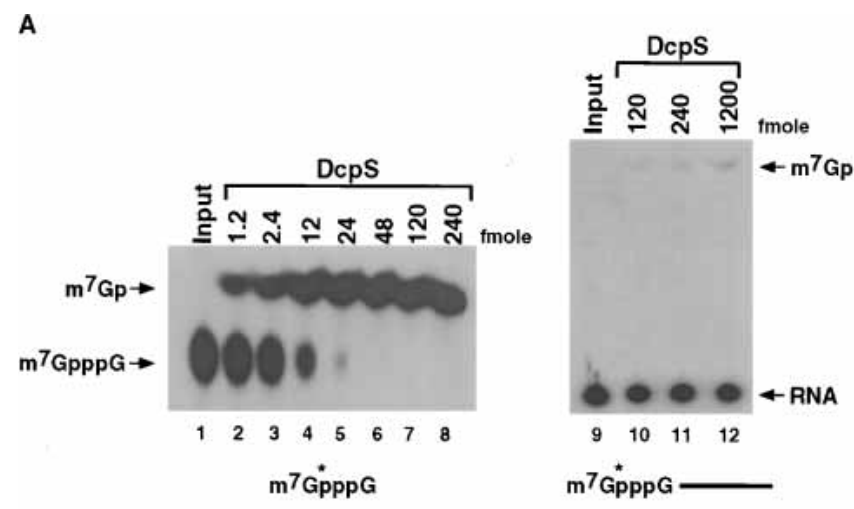

B

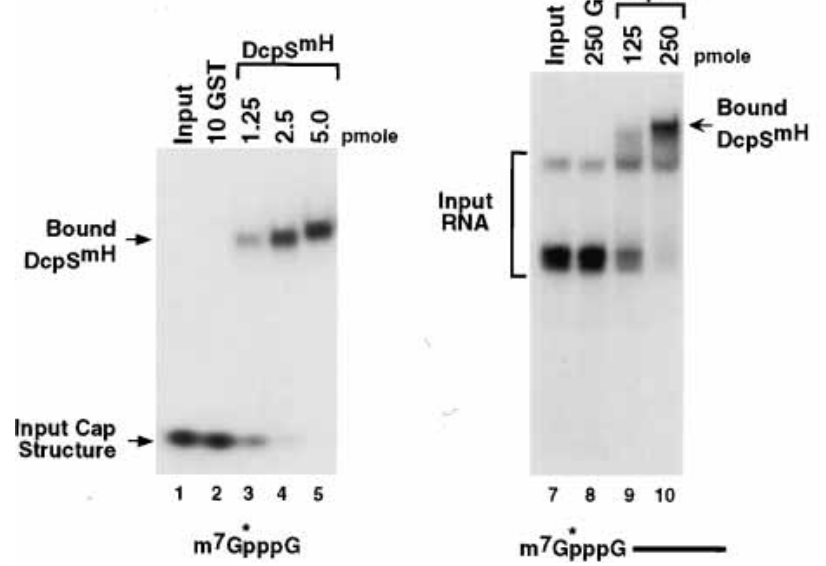

FIGURE 5. DcpS catalyzes the hydrolysis of cap structure but not capped RNA. (A) Decapping assays were carried out with the indicated amounts of His-DcpS. Left panel: ${ }^{32} \mathrm{P}$-labeled cap structure was used as substrate. Right panel: ${ }^{32} \mathrm{P}$-labeled cap containing a track of 16 guanosines at the $3^{\prime}$ end to minimize nonspecific $3^{\prime}$ end degradation (Wang and Kiledjian 2001) was used. The substrates are schematically represented at the bottom; the line denoting the RNA and migration of the cold standards are indicated. (B) EMSA of DcpS HIT mutant $\mathrm{DcpS}^{\mathrm{mH}}$ binding to ${ }^{32} \mathrm{P}$-labeled cap structure (left panel) or ${ }^{32} \mathrm{P}$ caplabeled RNA substrates (right panel) using the indicated amount of protein. The glutathione S-transferase domain was used as a negative control (GST; lanes 2,8). The input cap structure, capped RNA, and the corresponding bound complex are indicated.
TABLE 1. DcpS binding

\begin{tabular}{lc}
\hline Binding of DcpS ${ }^{\mathrm{mH}}$ to: & $\mathrm{k}_{\mathrm{d}}(\mu \mathrm{M})^{\mathrm{a}}$ \\
\hline Cap structure ( $\mathrm{m}^{7} \mathrm{G}^{*}$ pppG) & 0.075 \\
Capped RNA (m $\mathrm{G}^{*}$ ppp-RNA) & 1.2 \\
Uncapped RNA (*ppp-RNA) & $>>1$
\end{tabular}

a Dissociation constant determined as the concentration of His$\mathrm{DcpS}^{\mathrm{mH}}$ protein at which $50 \%$ of the labeled cap analog substrate was bound. Average of three independent experiments is indicated.

almost $100 \%$ of the substrate was decapped with 24 fmoles of DcpS (Fig. 5A, lane 5). Conversely, at the highest concentration of DcpS used in this assay (1200 fmoles), the capped RNA was hydrolyzed $<2 \%$ (Fig. $5 \mathrm{~A}$, lane 12 ). Therefore DcpS has at least a 2500-fold higher capacity to hydrolyze the cap structure substrate relative to capped RNA substrate.

We next determined whether a correlation existed between the inability of DcpS to hydrolyze capped RNA and its capacity to bind capped RNA, using an EMSA. As expected, binding of the catalytically inactive $\mathrm{DcpS}^{\mathrm{mH}}$ to the ${ }^{32}$ P-labeled cap structure was detected (Fig. 5B, lanes 3-5). Surprisingly, binding to cap-labeled RNA was also detected, although higher amounts of protein were required to detect binding (Fig. 5B, lanes 9,10). The binding was dependent on the cap, because DcpS did not bind uncapped RNA with the same concentrations of protein (data not shown). A filter binding assay with limiting ${ }^{32} \mathrm{P}$-labeled substrate was used in the presence of increasing concentrations of DcpS to assess binding affinities. The dissociation constants were determined as the concentration of protein at which $50 \%$ of the substrate was bound. DcpS bound to cap structure with an apparent dissociation constant $\left(\mathrm{K}_{\mathrm{d}}\right)$ of $7.5 \times 10^{-8} \mathrm{M}$, whereas the apparent $\mathrm{K}_{\mathrm{d}}$ for capped RNA was $1.25 \times 10^{-6}$ $M$ (Table 1). No significant binding was detected to uncapped RNA with a $\mathrm{K}_{\mathrm{d}} \gg 10^{-6} \mathrm{M}$. These data indicate that DcpS is a cap binding protein that is capable of binding both cap structure and capped RNA, but is only capable of efficiently hydrolyzing cap structure.

\section{DcpS can efficiently compete with eIF4E for access to the cap structure}

Because DcpS is a cap binding protein, UV crosslinking analysis was used to determine the capacity of DcpS to compete for cap binding with the major cytoplasmic cap binding protein, eIF4E. A constant concentration of histidine-tagged eIF4E was preincubated with ${ }^{32} \mathrm{P}$-labeled cap structure followed by addition of an increasing titration of catalytically inactive DcpS ${ }^{\mathrm{mH}}$ mutant protein. Crosslinking of eIF4E under these assay conditions (Fig. 6A, lane 1) was efficiently competed by the addition of DcpS where $50 \%$ of eIF4E was displaced from the cap structure with a 400 -fold 

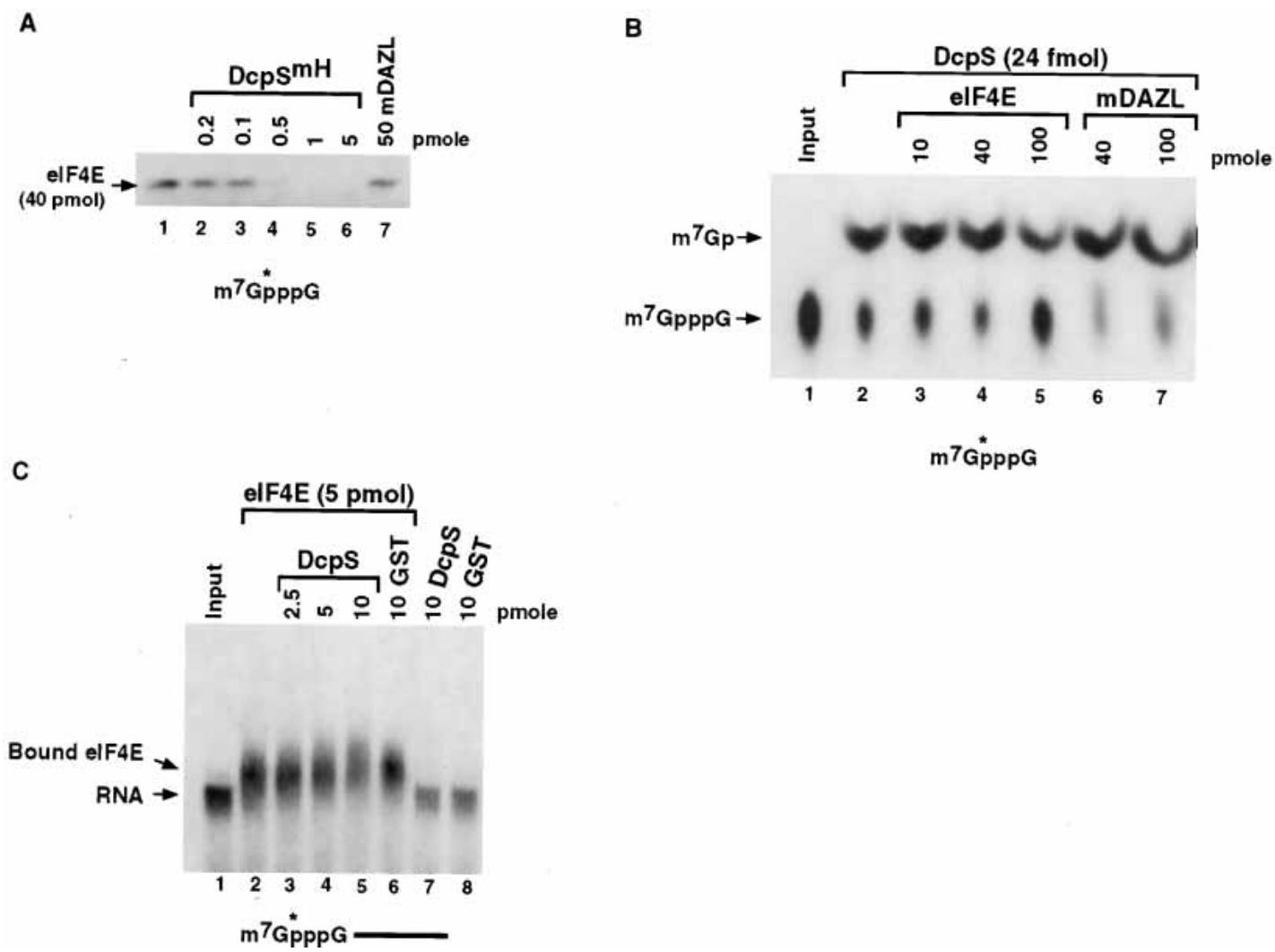

FIGURE 6. DcpS can displace eIF4E from the cap structure. (A) The ability of DcpS to displace eIF4E from the cap structure was tested. Forty pmoles of histidine-tagged eIF4E was preincubated with ${ }^{32} \mathrm{P}$-labeled cap structure on ice for $10 \mathrm{~min}$, followed by addition of the indicated amounts of histidine-tagged $\mathrm{DcpS}^{\mathrm{mH}}$ for an additional $10 \mathrm{~min}$ (lanes 1-6). The reactions were subsequently UV-crosslinked and resolved by SDSpolyacrylamide gel. The mDAZL RNA binding protein was used as a control (lane 7). DcpS can efficiently displace eIF4E from the cap structure. $(B)$ eIF4E is ineffective at inhibiting DcpS-mediated decapping. Indicated amounts of His-eIF4E (lanes 3-5) or control His-mDAZL (lanes 6,7) protein were preincubated with cap structure, followed by the addition of 24 fmoles of DcpS in a decapping assay. (C) DcpS is inefficient at removing eIF4E from capped RNA relative to cap structure. ${ }^{32} \mathrm{P}$ cap-labeled RNA was preincubated with 5 pmoles of His-eIF4E for 10 min on ice, and competed with the indicated amounts of competitor proteins. Migration of the input RNA and bound eIF4E-RNA complex are indicated on the left, and the RNA is denoted schematically at the bottom.

lower molar ratio of the $\mathrm{DcpS}^{\mathrm{mH}}$ protein (Fig. 6A, lane 3). Complete displacement of eIF4E was detected with an 80fold lower molar concentration of $\mathrm{DcpS}^{\mathrm{mH}}$ (Fig. 6A, lane 4). Addition of an unrelated RNA-binding protein had no affect (Fig. 6A, lane 7). eIF4E was equally ineffective at preventing hydrolysis of the cap structure by DcpS (Fig. 6B), where partial inhibition of decapping was only detected when a 4000-fold molar excess of eIF4E was preincubated with the cap structure (Fig. 6B, lane 5). However, consistent with the lower affinity of DcpS for capped RNA, DcpS was less efficient at competing eIF4E binding to capped RNA (Fig. 6C). Collectively, these data demonstrate that DcpS is able to compete effectively with eIF4E for cap structure, but not capped RNA.

\section{DcpS and hDcp2 decapping enzymes are both contained predominantly in the nucleus}

DcpS was initially identified as a cytoplasmic activity capable of hydrolyzing the residual cap structure following
mRNA decay (Wang and Kiledjian 2001). Subsequently, homologs of DcpS were reported to localize primarily within the nucleus of S. pombe (Salehi et al. 2002) and monkey cells (Kwasnicka et al. 2003). To determine the localization of human DcpS, we visualized the protein by indirect immunofluorescence using affinity-purified rabbit antisera directed against DcpS. As shown in Figure 7, the human DcpS protein is predominantly within the nucleus, although a low level of protein was also detected in the cytoplasm. As a comparison, localization of the endogenous hDcp 2 decapping enzymes was also carried out using affinity-purified antisera directed against hDcp2. Similar to previously described epitope-tagged exogenous hDcp2 localization (Ingelfinger et al. 2002; Lykke-Andersen 2002; van Dijk et al. 2002), the antisera marked cytoplasmic foci (Fig. 7B). Surprisingly, in addition to the cytoplasmic distribution, endogenous hDcp2 appears to be predominantly nuclear as assessed by indirect immunolocalization detected by confocal microscopy (Fig. 7B). The nuclear localization was not a consequence of the affinity-purified anti-hDcp2 antisera 
Endogenous DcpS

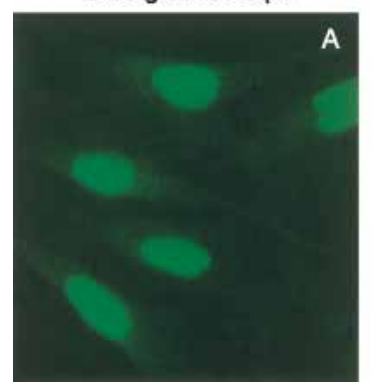

Endogenous hDcp2

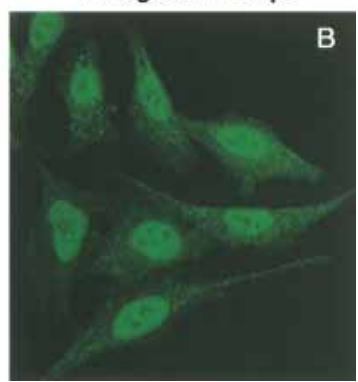

FIGURE 7. DcpS localizes to the nucleus and cytoplasm. (A) Endogenous DcpS was visualized in HeLa cells by indirect immunofluorescence microscopy using affinity-purified DcpS-specific rabbit antibody detected by FITC-conjugated goat antirabbit secondary antibody. (B) Endogenous hDcp2 protein in HeLa cells was detected with affinitypurified rabbit anti-Dcp2 antibody, and visualized by confocal microscopy using FITC-conjugated goat antirabbit secondary antibody.

crossreacting to a nuclear protein, as expression of a mycepitope-tagged hDcp2 had a similar nuclear and cytoplasmic distribution as that observed for the endogenous hDcp2 protein (data not shown). Similar localization was also detected using different fixation conditions (data not shown). These data demonstrate that both decapping enzymes are predominantly contained within the nuclear compartment. However, we have thus far not been able to biochemically copurify or coimmunopurify DcpS and hDcp2 from cell extract (data not shown). Collectively, the above immunofluorescence data indicate that both DcpS and hDcp2 are contained in the cytoplasm but are predominantly within the nucleus.

\section{DISCUSSION}

We present evidence that DcpS is a unique member of the HIT hydrolase protein family. It is a modular protein comprised of at least two distinct domains that are inactive individually but together reconstitute decapping activity in trans. One of these domains contains the 100-amino-acid HIT domain, demonstrating that this element is not sufficient for efficient substrate binding and hydrolysis activity as observed for other HIT motif proteins. We further demonstrate that DcpS can efficiently compete with eIF4E for binding cap structure, consistent with a role for DcpS in ensuring that eIF4E is not sequestered by byproducts of mRNA decay. Lastly, DcpS is shown to be predominantly a nuclear protein (as is $\mathrm{hDcp} 2$ ) by immunofluorescence microscopy.

Our analysis of Dcs1p and DcpS revealed that regions outside the HIT fold, namely the N-terminal domains, are essential for decapping activity. This point is underscored by the following observations. First, mutational analysis removing either the N-terminal 40 amino acids of Dcs1p or sequences following residue 33 in DcpS results in an inac- tive protein (Fig. 2). Second, dissection of DcpS into an $\mathrm{N}$-terminal domain and a C-terminal domain maintaining an intact HIT fold region abrogated the ability of the HIT fold to hydrolyze the cap, but interestingly, a mixture of the two domains in trans reconstituted decapping activity (Fig. 3). These data demonstrate that the N-terminal domain coordinates the activity of these proteins. This is further underscored by a functional decapping enzyme generated by the fusion of the $\mathrm{N}$-terminal domain of the catalytically active Dcs1p to the C-terminal domain of the catalytically inactive Dcs2p containing the HIT motif (Dcs1/2p). A Dcs $2 / 1 \mathrm{p}$ fusion protein containing the Dcs $2 \mathrm{p}$ N-terminal domain and the Dcs1p C-terminal domain was unable to catalyze cap hydrolysis (Fig. 1), demonstrating that the active state of the protein can be dictated by the composition of the N-terminal domain. During the course of this work, we obtained the cocrystal structure of DcpS bound to monomethylated cap analog ( $\mathrm{Gu}$ et al. 2004). Consistent with the data presented herein indicating that cap binding and hydrolysis of DcpS require the HIT fold as well as the $\mathrm{N}$-terminal domain, the structure revealed DcpS to be an asymmetric dimer containing distinct $\mathrm{N}$-terminal and $\mathrm{C}$ terminal domains that are separated by a hinge region. The structure illustrated that a productive active site is composed of amino acid residues emanating from both the $\mathrm{N}$ and C-terminal domains, several of which were critical for cap binding and hydrolysis (Gu et al. 2004).

Analyses of the N-terminal truncation of DcpS indicate that this domain primarily functions to facilitate cap binding. A direct correlation was detected between $\mathrm{N}$-terminal truncations that were able to hydrolyze the cap structure and those that can bind the cap. The DcpS ${ }^{\Delta \mathrm{N} 33}$ mutant, which retained decapping activity, was competent to bind the cap structure, whereas the DcpS ${ }^{\Delta \mathrm{N} 71}$ mutant, which was unable to hydrolyze the cap, was also unable to bind the cap (Fig. 4). Similarly, N-terminal truncations of Dcslp that were inactive for decapping were also unable to bind cap structure (data not shown). These data are in agreement with the observed structure of DcpS where removal of the terminal 33 amino acids would not disrupt the $\mathrm{N}$-terminal domain, whereas a larger truncation removing the first 71 amino acids would be expected to disrupt the overall structure of the N-terminal domain.

The generation of a functional decapping enzyme by substitution of the Dcs2p N-terminus with that of the Dcs1p $\mathrm{N}$-terminus demonstrates that Dcs2p contains a productive HIT motif capable of hydrolyzing a pyrophosphate linkage within a cap. At present, the function of Dcs $2 p$ is unclear. However, the lack of cap analog hydrolysis activity with recombinant Dcs2p and endogenous Dcs2p in yeast cells devoid of Dcs1p (Liu et al. 2002) indicates that Dcs2p is not involved in decapping the $\mathrm{m}^{7} \mathrm{GpppG}$ cap structure. Furthermore, Dcs2p also lacks the ability to catalyze the hydrolysis of capped RNA, indicating that it does not have a Dcp2-like decapping activity (data not shown). Because 
Dcs2p contains a functional HIT hydrolase motif, it is currently unclear whether Dcs2p could be involved in the hydrolysis of modified cap structures and/or dinucleotides separated by a pyrophosphate linkage. Studies are under way to test these possibilities.

An interesting property of DcpS is its specificity to hydrolyze cap structure relative to capped RNA (Wang and Kiledjian 2001; Liu et al. 2002). DcpS preferentially hydrolyzes cap structure at least 2500-fold more efficiently than capped RNA (Fig. 5). Interestingly, DcpS was able to bind the cap structure of capped RNA, although at a 17-fold lower affinity than that of cap structure (Table 1). As the addition of uncapped RNA competitor did not interfere with DcpS-mediated hydrolysis of cap analog (S.-W. Liu and M. Kiledjian, unpubl.), it is unlikely that the RNA moiety competitively inhibits DcpS activity. Structural analysis of DcpS suggests that in addition to the lower binding affinity, the increased size and entropy of a longer RNA molecule might hinder closure of the enzyme and formation of a productive decapping complex (Gu et al. 2004).

The S. pombe homolog of DcpS, Nhmlp, was recently identified as an enzyme capable of catalyzing the decapping of intact capped RNA (Salehi et al. 2002). The reason for the different decapping properties of Nhmlp compared to DcpS or Dcs1p is not obvious, considering the conservation of critical residues among these proteins as determined by the structure of DcpS. On the basis of the conservation, we would predict that Nhm1p also contains scavenger-decapping activity that will efficiently function on cap structure. Further analyses are necessary to determine the relative decapping efficiency of Nhm1p for cap structure versus capped RNA.

At least one function of DcpS is to hydrolyze the cap structure remaining after $3^{\prime}$ to $5^{\prime}$ exoribonucleolytic decay of the mRNA in both yeast cells and mammalian extract (Wang and Kiledjian 2001; Liu et al. 2002; Rodgers et al. 2002). A functional consequence of this hydrolysis activity could be to eliminate the removal of a potential substrate that can sequester the cytoplasmic eIF4E cap binding protein. The ability of DcpS to efficiently hydrolyze the cap structure in the presence of excess eIF4E is consistent with this hypothesis. Furthermore, the lower affinity of eIF4E to $\mathrm{m}^{7} \mathrm{GMP}$ relative to cap structure (Niedzwiecka et al. 2002; Zuberek et al. 2003) also supports such a function. Despite the ability of DcpS to bind the cap of a capped RNA, its relatively lower capacity to compete with eIF4E for capped RNA and its inability to catalyze the hydrolysis of capped RNA appear to provide a multilevel regulatory mechanism to ensure that capped RNAs are not prematurely hydrolyzed prior to degradation of the mRNA body. The relative lower efficiency of DcpS to displace eIF4E from capped RNA could also serve to minimize potential competition with eIF4E for capped mRNA, thus preventing potential interference with mRNA translation. Interesting questions remain: when during the demise of an mRNA does eIF4E dissociate from the cap and when does DcpS gain access to the cap? Curiously, Nhm1p was initially isolated as a protein associated with the $S$. pombe eIF4F cap binding complex (Salehi et al. 2002). A more detailed analysis of the affinities of eIF4E and DcpS to capped RNAs of varying lengths as well as additional proteins that can associate with the cap including PARN (Dehlin et al. 2000; Gao et al. 2000; Martinez et al. 2000) and the poly(A) binding protein PABP (Khanna and Kiledjian 2004) will begin to address the interplay between the cap and cap binding proteins during degradation.

Our data show that DcpS is mainly localized to the nucleus with a lower distribution in the cytoplasm. This is in addition to our initial biochemical identification of DcpS which indicated that DcpS protein and decapping activity were located in the cytoplasm (Wang and Kiledjian 2001; Liu et al. 2002). Conversely, the S. pombe (Salehi et al. 2002) and monkey homologs of DcpS (Kwasnicka et al. 2003) were also shown to be nuclear by immunofluorescence microscopy. In addition to the nuclear localization, DcpS was further shown to localize to a distinct perinuclear location in Cos cells (Kwasnicka et al. 2003). We have been unable to detect a similar perinuclear staining with either the endogenous DcpS (Fig. 7) or transiently expressed myc-tagged DcpS (X. Jiao and M. Kiledjian, unpubl.). Whether the discrepancy is due to the different species of cells used (Cos vs. HeLa) or a particular parameter of the cell (i.e., confluence or stress conditions) is currently unknown. Our demonstration that the endogenous hDcp2 protein is also predominantly nuclear implies a novel nuclear role for this mRNA decapping enzyme that was not previously anticipated. Previous immunofluorescence of transiently expressed tagged hDcp2 (Ingelfinger et al. 2002; LykkeAndersen 2002; van Dijk et al. 2002) and biochemical fractionation of hDcp2 (Wang et al. 2002) indicated that hDcp2 was predominantly a cytoplasmic protein. At present it is not clear what the precise nuclear functions for the DcpS and $\mathrm{hDcp} 2$ decapping enzymes are, but hydrolyzing the cap of aberrant transcripts is a likely possibility. It is intriguing that a third decapping activity corresponding to a U8 RNA binding protein (X29) was recently reported; X29 is also localized primarily to the nucleus and can hydrolyze the pyrophosphate linkage of both methylated and unmethylated capped RNA and was proposed to function in U8 RNA decapping (Ghosh et al. 2004). Future studies will address the possible role of $\mathrm{hDcp} 2$ and $\mathrm{DcpS}$ in the nucleus.

\section{MATERIALS AND METHODS}

\section{Plasmid construction}

Plasmids expressing amino terminal histidine-tagged recombinant proteins for DcpS (pET28-DcpS), Dcs1p (pET28-Dcs1 formerly called pET28 yDcpS), and Dcs2p (pET28-Dcs2, formerly pET28YOR173W) have been described (Liu et al. 2002). The pET28- 
Dcs1/2 encodes a chimeric protein containing amino acids 1-210 of Dcs1p and 254-397 of Dcs2p. It was generated by replacing the BamHI to PvuI fragment of pET28-Dcs2 with the corresponding fragment of pET28-Dcs1. The pET28-Dcs $2 / 1$ plasmid encodes a chimeric protein containing amino acids $1-253$ of Dcs $2 p$ and amino acids $211-350$ of Dcs1p. It was generated by replacing the BamHI to PvuI fragment of pET28-Dcs1 with the corresponding region of pET28-Dcs2.

The plasmid pET28-Dcs1 ${ }^{\Delta \mathrm{N} 40}$ encoding Dcs1p amino acids $41-$ 350 was generated by PCR amplification of sequences corresponding to these amino acids with a primer set introducing a BamHI site on the $5^{\prime}$ end and an XhoI site at the $3^{\prime}$ end of the PCR product (5'-AGTGGATCCGCTATTATCACGGCTGAA AAG-3' and $5^{\prime}$-CAGCCCTCGAGTTATTTAAAACCGTTCAC-3'). The PCR product was digested with BamHI and XhoI and inserted into the same sites of pET28a (Novagen). The plasmid pET28$D c s 1^{\Delta \mathrm{N} 81}$, encoding Dcs1p amino acids $82-250$, was generated by digesting the pET28-Dcs1 plasmid with NheI and EcoRI, the ends filled in with Klenow fragment and self-ligated. The plasmid pET28-Dcs1 ${ }^{\Delta \mathrm{C} 285}$, which encodes Dcs1p amino acids 1-284, was generated by digesting the pET28-Dcs1 plasmid with SacII and XhoI, the ends filled in with T4 DNA polymerase and self-ligated.

The plasmid pET28-DcpS $\Delta$ N33 encoding DcpS amino acids 34-337 was generated by PCR amplification using the forward primer, 5'-ATTGGATCCAATGGTACCTGTGCTCCTGTC-3' and the reverse primer, 5' -TCTCGAGTCAGCTTTGCTGAGCCTCCTG$3^{\prime}$ and inserted into pET28a as described for pET28-Dcs $1 \Delta N 40$. The plasmid pET28-DcpS $\Delta$ N71, which encodes DcpS amino acids 72-337, was generated by digesting pET28-hDcpS with NdeI and StuI. The resulting ends were filled in with Klenow fragment and self-ligated. The pET28-DcpS1-274 plasmid encoding DcpS amino acids 1-274 was generated by PCR with the following primers, 5' -AGGATCCCGCCTCCGCGGCAGCATG-3' and 5' -TTACTC GAGGTAGTAGGAGGGCAGGTAGTG-3' that introduce a BamHI and XhoI site, respectively. The PCR product was cloned into the same sites of pET28a. The plasmid pET-DcpSH277N expressing the HIT mutant protein DcpS ${ }^{\mathrm{mH}}$ which substitutes an asparagine for the active site histidine at position 277 was described (Liu et al. 2002). All of the above pET28a-based plasmids produce a recombinant protein containing a histidine-tag at the amino terminus.

Plasmids expressing DcpS or its truncations that lack a tag were generated by PCR amplification of either full-length DcpS or DcpS sequences from amino acids 1-147 and 149-337 and inserted into to the pSMT3 TOPO directional vector (Mossessova and Lima 2000; Invitrogen) to generate the plasmids pSMT3-hDcpS, pSMT3-hDcpS(1-147), and pSMT3-hDcpS(149-337), respectively. The murine eIF4E protein expression plasmid pET28-eIF4E was constructed by removal of the eIF4E coding region with BamHI and XhoI from the pPROEX-meIF4E plasmid (kindly provided by A.C. Gingras and N. Sonenberg, McGill Univ.) and inserted into the same sites of pET28a. The pGEX-mDAZL plasmid encoding the glutathione S-transferase (GST)-mDAZL fusion protein was obtained as described (Jiao et al. 2002).

\section{Recombinant protein expression and purification}

Recombinant proteins expressed from the pET vectors were generated in E. coli BL21(DE3) cells induced with $0.4 \mathrm{mM}$ IPTG and purified according to the manufacturer (Novagen), except that 300
$\mathrm{mM}$ urea was included in the binding buffer. Protein eluted from the nickel column was dialyzed against PBS $(0.14 \mathrm{M} \mathrm{NaCl}, 2.7 \mathrm{mM}$ $\left.\mathrm{KCl}, 1.5 \mathrm{mM} \mathrm{KH}_{2} \mathrm{PO}_{4}, 8.1 \mathrm{mM} \mathrm{Na} \mathrm{HPO}_{4}, \mathrm{pH} 7.4\right)$ and concentrated by Centricon centrifugal filter columns (Amicon). The $D c s 1^{\Delta C 285}$ and $D c p S^{1-274}$ proteins were purified under denaturing conditions with $4 \mathrm{M}$ urea according to the manufacturer's instructions (Novagen) and dialyzed against renaturing buffer $(50 \mathrm{mM}$ Tris- $\mathrm{HCl}, 500 \mathrm{mM}$ L-arginine, $5 \mathrm{mM}$ EDTA, 0.4\% PEG 4000, 5 $\mathrm{mM}$ reduced Glutathione, $1 \mathrm{mM}$ oxidized glutathione) overnight to remove the urea. The renaturing buffer was subsequently replaced by PBS in a stepwise manner by concentration using Centricon centrifugal filtration. The GST-mDAZL protein was purified by glutathione beads as described (Jiao et al. 2002) except that $300 \mathrm{mM}$ urea was included in the wash buffer. Proteins expressed from the pSMT3 vector were expressed in E. coli BL21 (DE3) CodonPlus RIL cells (Novagen). Proteins were initially purified by metal-affinity chromatography under native conditions as above and subsequently subjected to Ulp1 proteolysis to remove the $\mathrm{His}_{6}-\mathrm{Smt} 3$ tag (Mossessova and Lima 2000). The resulting protein would contain two extra amino acids (Ser-Leu) at the N-terminal ends, and were further purified by gel filtration (Superdex 75, Pharmacia).

\section{Generation of labeled RNA and cap structures}

Unlabeled, uncapped RNA corresponding to the pcDNA3 polylinker spanning from the SP6 promoter to the T7 promoter (pcP) with 16 guanosines at the $3^{\prime}$ end was transcribed by SP6 RNA polymerase from a PCR-generated template using the primers $5^{\prime}$-CGATTTAGGTGACACTATAG- $3^{\prime}$ and $5^{\prime}$-CCCCCCCCCC CCCCCCCGTAATACGACTCACTATAGGG-3'. Cap labeled RNA was generated with the vaccinia virus capping enzyme utilizing $\alpha-{ }^{32} \mathrm{P}$ GTP and $S$-adenosyl-methionine (SAM) to label the first phosphate within the cap relative to the methylated guanosine (m7G* $\mathrm{mppG}^{*}$ ) and the RNA gel-purified as described (Wang et al. 1999). Labeled cap structure without the RNA body was generated by treating the cap-labeled RNA with 1 unit Nuclease P1(Roche) for $1.5 \mathrm{~h}$ at $37^{\circ} \mathrm{C}$ to hydrolyze the RNA body leaving the intact cap structure as described (Wang and Kiledjian 2001). Uniformly labeled uncapped RNA was generated with SP6 RNA polymerase using $\alpha-{ }^{32} \mathrm{P}$ UTP according to the manufacturer (Promega).

\section{In vitro decapping assays}

Decapping assays were carried out with the indicated substrate and recombinant proteins in IVDA buffer $(10 \mathrm{mM}$ Tris $\mathrm{pH} 7.5,100$ $\mathrm{mM}$ KOAc, $2 \mathrm{mM}$ MgOAc, $2 \mathrm{mM}$ DTT, $10 \mathrm{mM}$ creatine phosphate, $0.1 \mathrm{mM}$ spermine) for $15 \mathrm{~min}$ at $37^{\circ} \mathrm{C}$. For the decapping assays shown in Figure $6 \mathrm{~B}$, the labeled cap structure was preincubated with the His-eIF4E protein for $10 \mathrm{~min}$, followed by the addition of DcpS and an additional 10 -min incubation at $37^{\circ} \mathrm{C}$. Decapping reactions were stopped by extracting once with phenol:chloroform (1:1). An aliquot of each reaction was spotted onto PEI-cellulose TLC plates (Sigma) that were prerun in $\mathrm{H}_{2} \mathrm{O}$ and air dried, and the products were developed with $0.45 \mathrm{M}\left(\mathrm{NH}_{4}\right)_{2} \mathrm{SO}_{4}$ at room temperature. The TLC plates were air dried and exposed to Kodak BioMax film or Phosphoroimager for quantitation. All quantitations were conducted with a Molecular Dynamics Phosphoroimager (Storm860) using ImageQuant-5 software. 


\section{Electrophoretic mobility shift assay (EMSA)}

EMSAs were carried out by incubating proteins with labeled cap structure or capped RNA in RNA binding buffer (RBB; $75 \mathrm{mM}$ $\mathrm{KCl}, 100 \mathrm{mM}$ Tris $\mathrm{HCl}, \mathrm{pH} 7.5,1.5 \mathrm{mM} \mathrm{MgCl}_{2}$, and $5 \mathrm{mM} \mathrm{DTT}$ ) containing $4 \mu \mathrm{g}$ heparin and 40 units RNase inhibitor (Promega) per reaction on ice for $15 \mathrm{~min}$. The resulting protein-cap or protein-RNA complexes were resolved on a $5.6 \%$ native polyacrylamide gel. The gel was dried and exposed to Kodak BioMax film.

\section{Filter binding assays}

Filter binding assays were carried out with an increasing concentration of DcpS ${ }^{\mathrm{mH}}$ incubated with ${ }^{32} \mathrm{P}$-labeled cap structure or ${ }^{32} \mathrm{P}$ cap labeled RNA similar to that described for the EMSAs above. Following the binding reaction, the samples were filtered through $0.2 \mu \mathrm{M}$ nitrocellulose filters (Millipore) prewashed with RBB to retain the protein-cap or protein-RNA complexes. The filters were subsequently washed twice with $2 \mathrm{~mL}$ ice-cold RBB to remove the nonspecifically bound labeled cap or capped RNA. The filters were air dried, and the amount of bound complex was determined by a liquid scintillation counter. The values were corrected by subtracting the background counts obtained from negative control reactions containing only the ${ }^{32} \mathrm{P}$-labeled substrate. The values for the bound cap-DcpS ${ }^{\mathrm{mH}}$ complex were plotted relative to $\mathrm{DcpS}^{\mathrm{mH}}$ concentration, and apparent dissociation constants were determined as the concentration of protein at which $50 \%$ of cap was bound (Wilson and Brewer 1999). The average of three independent experiments is reported.

\section{UV-crosslinking}

His-eIF4E was pre-incubated with ${ }^{32} \mathrm{P}$-labeled cap structure in IVDA buffer on ice for $10 \mathrm{~min}$, followed by addition of His$\mathrm{DcpS}^{\mathrm{mH}}$ for an additional 10-min incubation on ice. The samples were then covalently crosslinked by exposure to a $15 \mathrm{~W}$ germicidal UV lamp for $10 \mathrm{~min}$. Following crosslinking the samples were resolved by $12.5 \%$ SDS-PAGE and visualized by autoradiography.

\section{Immunofluorescence}

Generation of rabbit polyclonal antisera for His-tagged DcpS and hDcp2 were described by Liu et al. (2002) and Wang et al. (2002), respectively. The respective antibodies were affinity-purified with GST-fusion protein coupled to HiTrap affinity columns according to the manufacturer (Amersham Biosciences). HeLa cells were grown on coverslips in six-well plates and used for the immunofluorescence. Cover slips containing the cells were washed with PBS and fixed for $30 \mathrm{~min}$ in $2 \%$ formaldehyde in PBS and permeabilized for $3 \mathrm{~min}$ in acetone at $-20^{\circ} \mathrm{C}$. Cells were blocked with $\mathrm{PBS} / 3 \% \mathrm{BSA}$ for $30 \mathrm{~min}$ at room temperature and incubated with the primary antisera diluted in same solution for $1 \mathrm{~h}$. Slides were washed three times in PBS and incubated with secondary antibody for $1 \mathrm{~h}$ at room temperature, and subsequently washed in PBS and mounted with Fluoromount-G media (Southern Biotechnology). Affinity-purified rabbit polyclonal antisera was used as the primary antibody to detect endogenous DcpS or hDcp2. The secondary antibody consisted of fluorescein (FITC)-conjugated goat an- tirabbit IgG secondary (Jackson ImmunoResearch) antibody at a 1:80 dilution. The image in Figure 7A was obtained with a Zeiss Axiophot epifluorescence microscope, and the confocal image in Figure 7B was obtained with a Zeiss LSM 510 confocal microscope.

\section{ACKNOWLEDGMENTS}

We thank N. Kane-Goldsmith and the Keck Neuroscience Imaging Facility for assistance with the confocal microscopy, A.C. Gingras and N. Sonenberg for providing the eIF4E plasmid, and members of the Kiledjian lab for helpful discussions and critical reading of the manuscript. This work was supported by NIH funds GM61906 to C.D.L and DK51611 to M.K.

The publication costs of this article were defrayed in part by payment of page charges. This article must therefore be hereby marked "advertisement" in accordance with 18 USC section 1734 solely to indicate this fact.

Received April 14, 2004; accepted June 8, 2004.

\section{REFERENCES}

Bessman, M.J., Frick, D.N., and O'Handley, S.F. 1996. The MutT proteins or "Nudix" hydrolases, a family of versatile, widely distributed, "housecleaning" enzymes. J. Biol. Chem. 271: 2505925062.

Brenner, C. 2002. Hint, Fhit, and GalT: function, structure, evolution, and mechanism of three branches of the histidine triad superfamily of nucleotide hydrolases and transferases. Biochemistry 41: 90039014.

Brenner, C., Garrison, P., Gilmour, J., Peisach, D., Ringe, D., Petsko, G.A., and Lowenstein, J.M. 1997. Crystal structures of HINT demonstrate that histidine triad proteins are GalT-related nucleotidebinding proteins. Nat. Struct. Biol. 4: 231-238.

Brenner, C., Bieganowski, P., Pace, H.C., and Huebner, K. 1999. The histidine triad superfamily of nucleotide-binding proteins. J. Cell. Physiol. 181: 179-187.

Dehlin, E., Wormington, M., Korner, C.G., and Wahle, E. 2000. Capdependent deadenylation of mRNA. EMBO J. 19: 1079-1086.

Dunckley, T. and Parker, R. 1999. The DCP2 protein is required for mRNA decapping in Saccharomyces cerevisiae and contains a functional MutT motif. EMBO J. 18: 5411-5422.

Gao, M., Fritz, D.T., Ford, L.P., and Wilusz, J. 2000. Interaction between a poly(A)-specific ribonuclease and the $5^{\prime}$ cap influences mRNA deadenylation rates in vitro. Mol. Cell 5: 479-488.

Ghosh, T., Peterson, B., Tomasevic, N., and Peculis, B.A. 2004. Xenopus U8 snoRNA binding protein is a conserved nuclear decapping enzyme. Mol. Cell 13: 817-828.

Gu, M., Fabrega, C., Liu, S.W., Liu, H., Kiledjian, M., and Lima, C.D. 2004. Insights into the structure, mechanism, and regulation of scavenger mRNA decapping activity. Mol. Cell 14: 67-80.

Ingelfinger, D., Arndt-Jovin, D.J., Luhrmann, R., and Achsel, T. 2002. The human Lsm1-7 proteins colocalize with the mRNA-degrading enzymes Dcp1/2 and Xrnl in distinct cytoplasmic foci. RNA 8: $1489-1501$

Jiao, X., Trifillis, P., and Kiledjian, M. 2002. Identification of target messenger RNA substrates for the murine deleted in Azoospermialike RNA-binding protein. Biol. Reprod. 66: 475-485.

Khanna, R. and Kiledjian, M. 2004. Poly(A)-binding-protein-mediated regulation of hDcp2 decapping in vitro. EMBO J. 23: 19681976.

Koonin, E.V. 1993. A highly conserved sequence motif defining the family of MutT-related proteins from eubacteria, eukaryotes and viruses. Nucleic Acids Res. 21: 4847. 
Kwasnicka, D.A., Krakowiak, A., Thacker, C., Brenner, C., and Vincent, S.R. 2003. Coordinate expression of NADPH-dependent flavin reductase, Fre-1, and Hint-related 7meGMP-directed hydrolase, DCS-1. J. Biol. Chem. 278: 39051-39058.

Lima, C.D., Klein, M.G., and Hendrickson, W.A. 1997. Structurebased analysis of catalysis and substrate definition in the HIT protein family. Science 278: 286-290.

Liu, H., Rodgers, N.D., Jiao, X., and Kiledjian, M. 2002. The scavenger mRNA decapping enzyme DcpS is a member of the HIT family of pyrophosphatases. EMBO J. 21: 4699-4708.

Lykke-Andersen, J. 2002. Identification of a human decapping complex associated with hUpf proteins in nonsense-mediated decay. Mol. Cell. Biol. 22: 8114-8121.

Martinez, J., Ren, Y.G., Thuresson, A.C., Hellman, U., Astrom, J., and Virtanen, A. 2000. A 54-kDa fragment of the Poly(A)-specific ribonuclease is an oligomeric, processive, and cap-interacting Poly(A)-specific 3' exonuclease. J. Biol. Chem. 275: 24222-24230.

Mejean, V., Salles, C., Bullions, L.C., Bessman, M.J., and Claverys, J.P. 1994. Characterization of the mutX gene of Streptococcus pneumoniae as a homologue of Escherichia coli mutT, and tentative definition of a catalytic domain of the dGTP pyrophosphohydrolases. Mol. Microbiol. 11: 323-330.

Mossessova, E. and Lima, C.D. 2000. Ulp1-SUMO crystal structure and genetic analysis reveal conserved interactions and a regulatory element essential for cell growth in yeast. Mol. Cell 5: 865-876.

Niedzwiecka, A., Marcotrigiano, J., Stepinski, J., Jankowska-Anyszka, M., Wyslouch-Cieszynska, A., Dadlez, M., Gingras, A.C., Mak, P., Darzynkiewicz, E., Sonenberg, N., et al. 2002. Biophysical studies of eIF4E cap-binding protein: recognition of mRNA $5^{\prime}$ cap structure and synthetic fragments of eIF4G and 4E-BP1 proteins. J. Mol. Biol. 319: 615-635.

Nuss, D.L. and Furuichi, Y. 1977. Characterization of the m7G(5')pppN-pyrophosphatase activity from HeLa cells. J. Biol. Chem. 252: 2815-2821.

Nuss, D.L., Furuichi, Y., Koch, G., and Shatkin, A.J. 1975. Detection in HeLa cell extracts of a 7-methyl guanosine specific enzyme activity that cleaves m7GpppNm. Cell 6: 21-27.

Pace, H.C., Garrison, P.N., Robinson, A.K., Barnes, L.D., Draganescu, A., Rosler, A., Blackburn, G.M., Siprashvili, Z., Croce, C.M., Huebner, K., et al. 1998. Genetic, biochemical, and crystallographic characterization of Fhit- substrate complexes as the active signaling form of Fhit. Proc. Natl. Acad. Sci. 95: 5484-5489.

Parker, R. and Song, H. 2004. The enzymes and control of eukaryotic mRNA turnover. Nat. Struct. Mol. Biol. 11: 121-127.

Piccirillo, C., Khanna, R., and Kiledjian, M. 2003. Functional characterization of the mammalian mRNA decapping enzyme hDcp2. RNA 9: 1138-1147.

Rodgers, N.D., Wang, Z., and Kiledjian, M. 2002. Regulated $\alpha$-globin mRNA decay is a cytoplasmic event proceeding through $3^{\prime}$-to- $5^{\prime}$ exosome-dependent decapping. RNA 8: 1526-1537.

Salehi, Z., Geffers, L., Vilela, C., Birkenhager, R., Ptushkina, M., Berthelot, K., Ferro, M., Gaskell, S., Hagan, I., Stapley, B., and McCarthy, J.E. 2002. A nuclear protein in Schizosaccharomyces pombe with homology to the human tumour suppressor Fhit has decapping activity. Mol. Microbiol. 46: 49-62.

Seraphin, B. 1992. The HIT protein family: a new family of proteins present in prokaryotes, yeast and mammals. DNA Seq. 3: 177179.

Steiger, M., Carr-Schmid, A., Schwartz, D.C., Kiledjian, M., and Parker, R. 2003. Analysis of recombinant yeast decapping enzyme. RNA 9: 231-238.

van Dijk, E., Cougot, N., Meyer, S., Babajko, S., Wahle, E., and Seraphin, B. 2002. Human Dcp2: A catalytically active mRNA decapping enzyme located in specific cytoplasmic structures. $E M B O$ J. 21: 6915-6924.

Wang, Z. and Kiledjian, M. 2001. Functional link between the mammalian exosome and mRNA decapping. Cell 107: 751-762.

Wang, Z., Day, N., Trifillis, P., and Kiledjian, M. 1999. An mRNA stability complex functions with poly(A)-binding protein to stabilize mRNA in vitro. Mol. Cell. Biol. 19: 4552-4560.

Wang, Z., Jiao, X., Carr-Schmid, A., and Kiledjian, M. 2002. The hDcp2 protein is a mammalian mRNA decapping enzyme. Proc. Natl. Acad. Sci. 99: 12663-12668.

Wilson, G.M. and Brewer, G. 1999. Identification and characterization of proteins binding A + U-rich elements. Methods 17: 74-83.

Zuberek, J., Jemielity, J., Niedzwiecka, A., Stepinski, J., WyslouchCieszynska, A., Stolarski, R., and Darzynkiewicz, E. 2003. Influence of the length of the phosphate chain in mRNA 5' cap analogues on their interaction with eukaryotic initiation factor 4E. Nucleosides Nucleotides Nucleic Acids 22: 1707-1710. 

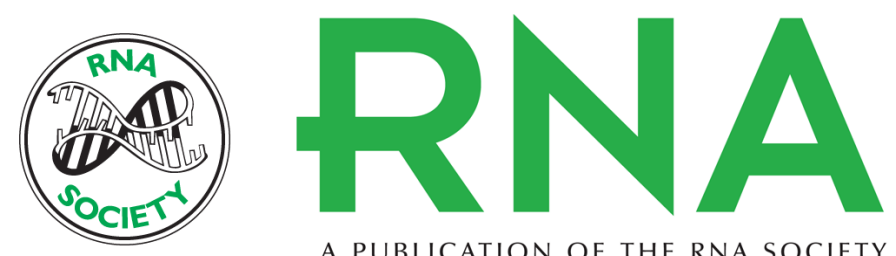

A PUBLICATION OF THE RNA SOCIETY

\section{Functional analysis of mRNA scavenger decapping enzymes}

SHIN-WU LIU, XINFU JIAO, HUDAN LIU, et al.

RNA 2004 10: 1412-1422

References This article cites 36 articles, 17 of which can be accessed free at:

http://rnajournal.cshlp.org/content/10/9/1412.full.html\#ref-list-1

License

Email Alerting Receive free email alerts when new articles cite this article - sign up in the box at the Service top right corner of the article or click here.

To subscribe to $R N A$ go to:

http://rnajournal.cshlp.org/subscriptions 